\title{
Análise da viabilidade econômica, ambiental e social da implantação do sistema de reúso de água em uma indústria de revestimento cerâmico
}

\section{Analysis of the economic, environmental and social viability of the implantation of the water reuse system in a ceramic coating industry $19 / 02 / 2019$ \\ Data de aprovação: $04 / 11 / 2019$}

Data de entrada:

Vanessa Silva Chaves $^{1 *}$ | Tatiana Máximo Almeida Albuquerque ${ }^{1}$ | Luciana Coêlho Mendonça ${ }^{1}$

DOI: https://doi.org/10.36659/dae.2021.001

ORCID ID

Chaves VS (iD https://orcid.org/0000-0003-1973-2597
Albuquerque TMA iD https://orcid.org/0000-0002-7636-9192 Mendonça LC (iD) https://orcid.org/0000-0001-6979-8135

\section{Resumo}

Nas circunstâncias de escassez hídrica, cresce a adoção de técnicas de uso racional de água, dentre as quais o reúso, que vem sendo utilizado por vários setores usuários desse recurso, inclusive a indústria. Diante desse cenário, este trabalho teve por objetivo principal analisar a viabilidade da implementação do sistema de reúso de água em uma indústria de revestimento cerâmico, localizada no estado de Sergipe, considerando aspectos econômicos, ambientais e sociais. Para isso foram realizadas entrevistas, visitas locais, questionários, ensaios laboratoriais, projeto e orçamento da obra, por meio dos quais foram coletados os dados necessários para o desenvolvimento do trabalho. Concluiu-se que é viável a implantação do sistema de reúso em uma indústria de revestimento cerâmico, pois, apesar de não promover retorno de investimento para a indústria em estudo, possibilita uma alta redução de consumo e tem boa aceitabilidade, contribuindo para o meio ambiente e a atenuação da crise.

Palavras-chave: Uso racional. Reúso de água. Indústria.

\section{Abstract}

In water scarcity circumstances, the adoption of rational water use techniques grows. Reuse is an example of these techniques that has been used by several sectors users of water, including the industry. By this scenario, the main objective of this work was to analyse the feasibility of the implementation of the water reuse system in a ceramic coating industry, located in the state of Sergipe, considering economic, environmental and social aspects. For this, interviews, local visits, questionnaires, laboratory tests, project and budget of the work were carried out through which the necessary data for the development of the system were collected. It was concluded that it is feasible to implement the reuse system in a ceramic coating industry, since, it allows a high reduction of consumption and has good acceptability, contributing to the environment and mitigation of the crisis. Although it does not promote return on investment for the industry under study nowadays.

Keywords: Rational use. Reuse. Industry.

\footnotetext{
1 Universidade Federal de Sergipe - São Cristóvão - Sergipe - Brasil.

* Autora correspondente: chaves_vanessaayahoo.com.br.
} 


\section{INTRODUÇÃO}

O problema de escassez hídrica tem se espalhado por várias partes do mundo, principalmente, pelo elevado crescimento populacional, associado à poluição hídrica e ao desperdício. O Brasil é um país privilegiado por deter um grande potencial hídrico, no entanto não está isento da crise. Segundo Setti et al. (2000), o problema de escassez hídrica no Brasil é consequência, além de causas naturais, da combinação entre o crescimento exagerado das demandas localizadas e da degradação da qualidade das águas, originários dos desenfreados processos de urbanização, expansão agrícola e industrialização.

Em 2015, na região Nordeste do Brasil, todos os estados notificaram ocorrência de eventos de seca. Em 2018, a seca nessa região atingiu o sétimo ano consecutivo, trazendo múltiplos impactos para a população (ANA, 2016; CIRILO, 2015).

Na maioria dos casos, para minimizar os impactos gerados pela crise hídrica, os governos federais e estaduais optam pela implementação de medidas emergenciais, como racionamento, utilização de carros-pipa e medidas regulatórias drásticas, como a diminuição da vazão defluente de reservatórios. No Rio São Francisco, por exemplo, de 2013 até 2018, a vazão foi reduzida de 1300 a 550 m³/s, conforme a Resolução da Agência Nacional de Água No 90/2018 (ANA, 2018). Essa necessidade de agir de forma emergencial, que causa muitos transtornos à população, pode ser evitada com a implementação de um planejamento e gerenciamento mais adequado dos recursos hídricos (ANA, 2015a; ANA, 2017).

No contexto de gerenciamento dos recursos hídricos, tem-se destacado o desenvolvimento de técnicas e propostas que objetivam o uso racional de água. De forma a reconsiderar o antigo conceito de solução para o problema de escassez, que seria inicialmente a expansão da oferta de água (construção de barragens, canais, trans- posições), cresce a ideia do gerenciamento de demanda, que consiste na prática da adoção de medidas que incentivem o uso racional de água, sem prejuízo nos atributos de higiene e conforto dos sistemas originais (ALBUQQUERQQUE, 2004).

Dentre as técnicas de uso racional, fortalece-se, cada vez mais, o reúso, como alternativa para harmonizar a relação entre a demanda e oferta de água. Com o auxílio de tecnologias, uma água, depois de utilizada, consegue ser adaptada a um novo uso, sendo necessário passar por tratamento ou não (a depender do uso a qual será destinada), colaborando com a redução da escassez hídrica (MIERZWA, 2002; ALBUQUUERQUE, 2004).

O estudo da implementação do reúso de água tem se expandido para os diferentes usuários desse recurso, inclusive a indústria. De acordo com a ANA (2015b), o setor industrial é responsável por $15 \%$ da vazão retirada total no Brasil, o que desperta grande preocupação com relação ao problema de escassez, seja pelo consumo excessivo ou pela poluição dos corpos d'água, consequência do lançamento de efluentes. Diante disso, a indústria tem sido constante alvo de experiências de implementação de alternativas de minimização do consumo, conforme apresentado nos estudos realizados por Lopes (2006) e Ribeiro (2011).

A indústria de revestimento cerâmico, por exemplo, possui altos índices de consumo de água e, sendo o Brasil um grande produtor ( $2^{\circ}$ maior do mundo em 2014, de acordo com a Associação Nacional dos Fabricantes de Cerâmica), esse ramo da indústria merece uma atenção especial quando se trata de gerenciamento dos recursos hídricos (ANFACER, 2014).

Diante desse contexto, o presente trabalho tem como objetivo analisar a viabilidade da implementação do sistema de reúso de água na indústria, considerando os aspectos econômicos, ambientais e sociais. 
Para tanto, foi realizado um estudo de caso em uma indústria de revestimento cerâmico, localizada no Estado de Sergipe, com o intuito de investigar o sistema de reúso já implementado na empresa, verificar a sua eficiência, quantificar o custo de construção, mensurar a redução de consumo de água pós implantação e funcionamento do sistema e analisar o nível de aceitabilidade das pessoas ao consumo de uma água de reúso.

\section{METODOLOGIA}

\section{1 Área de estudo}

A empresa estudada atua no setor cerâmico, tendo como objetivo produzir pisos e revestimentos para o mercado interno e externo.
A indústria de cerâmica, objeto de estudo, fica localizada no estado de Sergipe (que apresenta cerca de $38 \%$ de sua área com clima semiárido) e dispõe de uma extensa área territorial, contemplando as jazidas, os pátios de secagem e os galpões que abrigam o maquinário. Possui, aproximadamente, 270 funcionários, que trabalham em turnos administrativos e turnos de revezamento em duas linhas de produção.

O processo de produção acontece por via seca, ou seja, as placas cerâmicas são feitas por processo de moagem a seco das matérias-primas, por moinhos de martelo e pendulares (ABCERAM, 2017). O processo produtivo obedece às etapas apresentadas na Fig. 1.

Figura 1 - Etapas do processo de produção da indústria.

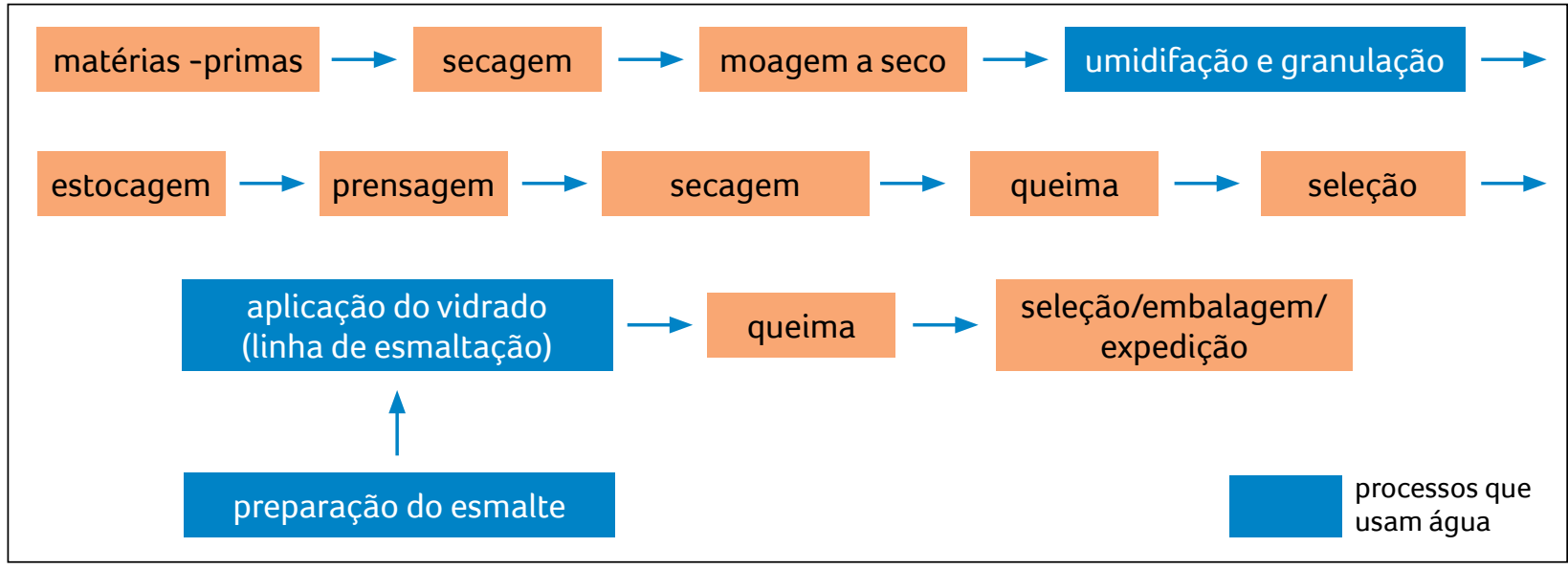

Fonte: Adaptado de ABCERAM (2017)

Como pode ser visto na Fig. 1, no processo de produção a seco a água é utilizada em duas etapas principais: antes da prensagem, ou seja, na etapa de granulação, e na linha de esmaltação. Além disso, na indústria, a água é utilizada para consumo humano (ambientes sanitários, bebedouros e refeitório), nas operações de limpeza dos equipamentos, do piso da fábrica e dos banheiros e na preparação dos esmaltes.
Vale ressaltar que, na etapa de granulação, o grau de umidificação da massa moída a seco adotado pela empresa é de $8 \%$ do peso seco, permitindo a formação de um material granulado, que é enviado para a prensagem. Ainda, a tinta utilizada pela indústria cerâmica não é produzida na empresa.

A indústria estudada possui uma característica importante de já utilizar o reúso de água em seu processo de produção, pois dispõe de uma pe- 
quena Estação de Tratamento de Efluentes (ETE), composta por 4 tanques de sedimentação, com capacidade de 16.000 litros cada, que tratam os efluentes da linha de esmaltação e da limpeza da área de fabricação de esmalte. $O$ efluente tratado é reutilizado no processo na etapa de granulação.

\subsection{Coleta de dados}

\subsubsection{Funcionamento da ETE e Quantidade de Efluente Tratado}

Para coletar os dados referentes ao funcionamento da ETE da indústria e a quantidade de efluente tratado, foram realizadas visitas técnicas para observação do processo e execução das entrevistas.

Durante as visitas em campo, foi observado todo o processo de tratamento, desde a coleta do efluente até a passagem pela última etapa e encaminhamento para reúso.

A entrevista foi realizada de forma não estruturada com o funcionário responsável pela ETE, que informou a quantidade de efluente tratado diariamente.

\subsubsection{Eficiência da ETE da indústria}

Para análise da eficiência da ETE instalada na indústria, foram realizados testes em laboratório, obedecendo os métodos padrões para o exame de água e águas residuais (Standard Methods for Examination of Water and Wastewater APHA, 2012).

Dos componentes típicos do efluente não tratado gerado na produção de revestimento cerâmico, foram analisados os materiais suspensos e sedimentados e a DQO (Demanda Química de Oxigênio), mas a composição química (cloreto, magnésio, potássio, alumínio, etc) não foi analisada por necessitar de ensaios muito específicos. Além disso, foram determinados $\mathrm{pH}$, cor e turbidez, que normalmente são altos no efluente de uma indús- tria de revestimento cerâmico, devido às partículas finas de esmaltes e minerais de argila.

Como as normas para fabricação de revestimento cerâmico não mencionam padrões para a qualidade da água nem a bibliografia consultada faz alguma recomendação, para verificar a eficiência do tratamento, a água atualmente utilizada pela indústria em seu processo de produção (água do poço) foi utilizada como referência. Os limites dos parâmetros a serem cumpridos foram estabelecidos por meio dos testes de qualidade da água captada nos poços.

\subsubsection{Custo de implementação}

Para quantificação do custo de implementação, foi elaborado o orçamento, incluindo os custos dos materiais e os encargos sociais, por meio de pesquisas de mercado e com o auxílio do software ORSE - Orçamento de Obras de Sergipe.

O ORSE é um software gratuito desenvolvido e disponibilizado pela CEHOP - Companhia Estadual de Habitação e Obras Públicas de Sergipe. Esse software possui um banco de dados composto por milhares de insumos, serviços e composições de preço unitário, que são atualizados mensalmente pela companhia, permitindo a elaboração de orçamentos de diferentes tipos de obra (CEHOP, 2017).

No ORSE, foi utilizada a base de dados do mês de janeiro de 2018.

\subsubsection{Viabilidade Econômica e Ambiental (Análise dos custos e da redução de consumo)}

Nesta etapa, com base na quantidade de efluente tratado e no orçamento elaborado, foi obtida a redução de consumo, em volume de água e em dinheiro (redução dos gastos nas contas de água), alcançada com a implementação do sistema de reúso. 


\subsubsection{Viabilidade Social (Aceitabilidade da água para reúso)}

Para aquisição dos dados referentes ao aspecto social, foi aplicado um questionário, a fim de avaliar a aceitabilidade ambiental e econômica dos gestores e funcionários da indústria em relação a uma água reutilizada.

O questionário, apresentado na Fig. 2, foi aplicado a uma amostra de funcionários e foram utilizados os Intervalos de Confiança (ICs) para a estimação dos parâmetros da população.

Como trata-se de variáveis qualitativas, a estimação por intervalo foi feita em função da Proporção Populacional $(\pi)$, para o qual o melhor estimador é a proporção amostral (p). Como não se sabe a respeito da variância da população, é indicado utilizar uma estimativa exagerada da amostra, supondo o máximo valor possível para o produto $p x(1-p)$, que ocorre quando a proporção é 0,5. A proporção amostral "p" tem média igual a " $\pi$ " e variância igual a $[\pi \times(1-\pi) n /]$ (REIS, 2012; BOLFARINE; BUSSAB, 2004).

Para o cálculo do erro máximo de estimação ou precisão do intervalo foi utilizada a Eq. 1, adotada quando $n x \quad p \geq 5$ e $n x(1-p) \geq 5$, já que a proporção amostral " $p$ " é binomial e só pode ser aproximada por uma distribuição normal satisfazendo essas condições (REIS, 2012).

$e_{0}=Z_{\frac{a}{2}} x \sqrt{\frac{p x(1-p}{n}}$

Em que:

$\mathrm{e}_{0}=$ erro máximo de estimação;

$Z_{\alpha / 2}=$ valor crítico para o grau de confiança desejado;

$\mathrm{p}=$ proporção de resultados favoráveis da variável na amostra;

$\mathrm{n}=$ tamanho da amostra.

Como a população é finita, com o tamanho (N) Conhecido e o tamanho da amostra (n) é maior que $5 \%$ de $\mathrm{N}$, foi preciso corrigir o erro máximo de estimação, utilizando a Eq. 2, para evitar que os limites do intervalo não fossem acurados (REIS, 2012).

$e_{0_{\text {corrigido }}}=e_{0} x \sqrt{\frac{N-n}{N-1}}$

Por fim, o IC foi construído, segundo a Eq. 3 (REIS, 2012).

$P\left(p-e_{0} \leq \mu \leq p+e_{0}\right)$

Figura 2 - Questionário de aceitabilidade do sistema de reúso de água.

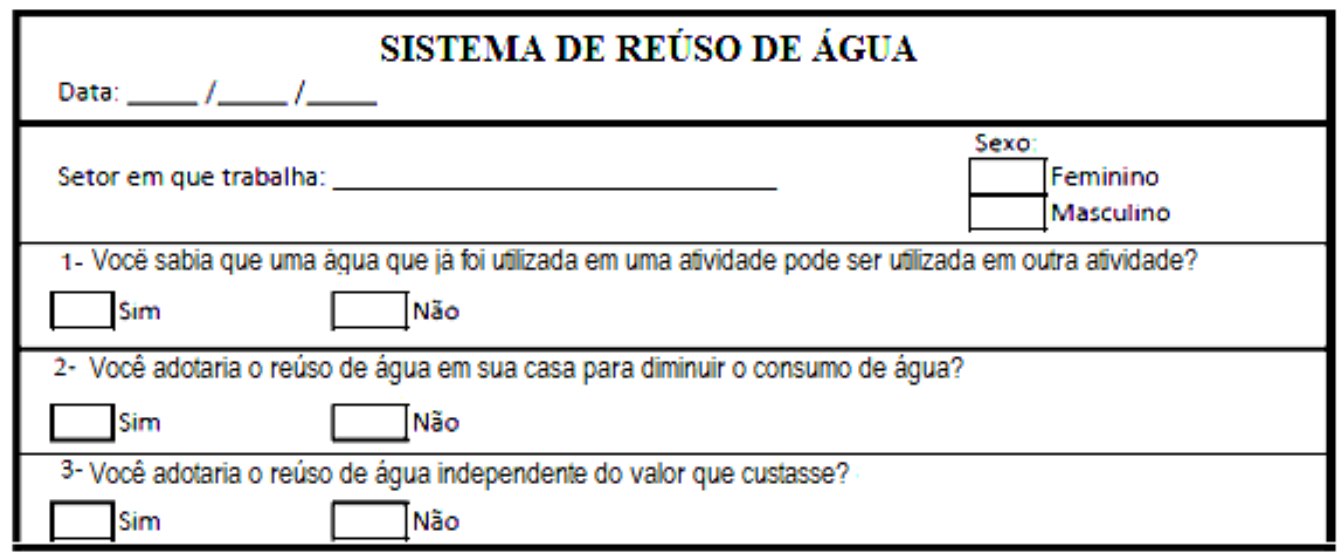

Fonte: Elaborada pelas autoras. 


\section{RESULTADOS E DISCUSSÕES}

\subsection{Funcionamento da ETE e Quantidade de Efluente Tratado}

No sistema de reúso da indústria de cerâmica, o efluente das linhas de esmaltação é captado por calhas contidas no piso da indústria e enviado por tubulação aérea até a ETE, com o auxílio de uma bomba, localizada nas proximidades de onde é gerado o efluente. Já o efluente do setor de fabricação de esmalte (limpeza dos tanques e do piso) percorre nas calhas até a ETE e, só aí, com ajuda de bomba, é enviado aos tanques para tratamento.

A ETE é composta por 4 tanques de 16.000 litros, sendo que 3 funcionam em batelada, ou seja, somente quando um tanque está cheio enche-se o seguinte. $O$ quarto tanque é utilizado para armazenamento do efluente pré-tratado e aplicação do cloro para desinfecção.

O enchimento de um tanque dura, em média, 11 horas. Quando cheio, são adicionados de 15 a 45 litros de polímero e, aproximadamente, 15 litros de um agente coagulante (decantador). 0 efluente passa por 5 minutos de agitação (somente os tanques 1, 2 e 3 possuem agitadores) e demora entre 30 a 40 minutos para sedimentar os sólidos. Eventualmente é, ainda, adicionada cal ao efluente (aproximadamente $3 \mathrm{~kg}$ ), para correção do $\mathrm{pH}$, quando este é inferior a $6.0 \mathrm{pH}$ deve estar entre 6,4 a 7,2 e é sempre verificado com o auxílio de fita medidora.

O efluente pré-tratado nos tanques 1, 2 e 3 é enviado para o tanque $4 \mathrm{com}$ auxílio de uma bomba, onde será adicionado cloro para desinfecção. O efluente tratado no tanque 4 é, ainda, encaminhado a um filtro de fluxo descendente, onde passa por 3 camadas de areia para posterior en- vio, com auxílio de bomba, ao início do processo de produção, mais precisamente, para a etapa de granulação da massa.

O resíduo do tanque 4 é recolhido e, com auxílio de uma bomba, enviado a um tanque de armazenamento. Desse tanque, também com auxílio de bomba, o resíduo é encaminhado para passagem em um filtro prensa, em que a água, recolhida por calha, volta para o início do tratamento e a massa volta para a mistura no início do processo produtivo da indústria, finalizando o sistema de reúso.

Após análise da ETE e realização da entrevista com o funcionário responsável, foi constatado que 12 tanques de efluente são tratados por semana, o que corresponde a $672.000 \mathrm{~L}$ mensais (considerando que cada tanque é enchido até $87,5 \%$ da sua capacidade, como indicado pelo gerente da empresa), e todo o efluente gerado na linha de esmaltação e o efluente da limpeza do piso e dos tanques do setor de fabricação de esmalte recebem tratamento e são aproveitados no processo de produção.

\subsection{Eficiência da ETE da Indústria}

Foram realizados os testes de qualidade da água utilizada pela indústria para a produção das peças (água do poço), do efluente bruto e do efluente tratado (proveniente do tanque 4). 0 teste de qualidade não foi realizado com o efluente após a passagem no filtro, pois não foi possível fazer a coleta, já que a saída é ligada diretamente ao início do processo de produção, sem ponto para captação.

Os resultados dos ensaios são apresentados na Tabela 1. 
Tabela 1 - Resultados dos testes que qualidade da água e do efluente da indústria.

\begin{tabular}{|c|c|c|c|c|}
\hline Parâmetro & Água do poço & $\begin{array}{l}\text { Efluente } \\
\text { Bruto (Eb) }\end{array}$ & Efluente tratado (Et) & Eficiência (\%) \\
\hline Sólidos totais (mg/L) & 1.075 & 12.842 & 1.498 & 88,3 \\
\hline Sólidos suspensos (mg/L) & 89 & 12.435 & 0 & 100,0 \\
\hline Sólidos sedimentáveis (mL/L) & 0,1 & 35 & $<0,1$ & $>99,7$ \\
\hline $\mathrm{pH}$ & 6,7 & 8,09 & 6,95 & - \\
\hline Cor (uC) & $>550$ & $>550$ & 48 & $>91,3$ \\
\hline Turbidez (uT) & 281 & 1.100 & 9 & $>99,4$ \\
\hline DQO (mg/L) & 33 & 598 & 99,5 & 83,4 \\
\hline DQQO filtrada (mg/L) & 7 & 87,5 & 95 & - \\
\hline
\end{tabular}

Analisando os resultados dos testes de qualidade da água do poço e do efluente tratado no tanque 4, observou-se que o método utilizado pela indústria apresenta uma boa eficiência de remoção para todos os parâmetros analisados (acima de $80 \%)$.

$\mathrm{O} \mathrm{pH}$ do efluente é semelhante ao da água do poço com valor dentro da neutralidade.

Comparando o efluente tratado com a água utilizada pela indústria em seu processo produtivo (água do poço), percebe-se que aquele apresenta qualidade superior na maioria dos parâmetros, exceto em relação aos sólidos totais e a DQQO. No entanto, sabe-se que os sólidos totais são compostos pelos sólidos suspensos e pelos sólidos dissolvidos. Pela Tabela 1, vê-se que a quantidade de sólidos suspensos presentes no efluente tratado é zero, ou seja, seus sólidos totais correspondem apenas aos sólidos dissolvidos, o que não representa um problema para uso no processo de produção.

O sistema de tratamento tem um bom desempenho de remoção de DQO $(83,4 \%)$ e, de maneira semelhante aos sólidos, a DQO do efluente da ETE apresenta matéria orgânica praticamente apenas na forma dissolvida.

Diante disso, percebeu-se que o filtro pelo qual o efluente é submetido ao sair do tanque 4 tem a função, apenas, de garantir segurança, caso haja algum problema no processo de tratamento realizado nos tanques. Neste caso, o filtro removeria uma parcela dos sólidos suspensos que escapassem do tratamento.

\subsection{Custo de implementação}

De acordo com o orçamento elaborado no ORSE, a implantação do projeto de reúso requer um investimento inicial de $\mathrm{R} \$ 263.310,24$.

\subsubsection{Viabilidade Econômica e Ambiental (Análise dos custos e da redução de consumo)}

O volume de água a ser reutilizado foi encontrado conforme apresentado anteriormente e corresponde a $168.000 \mathrm{~L} / \mathrm{semana}$, ou seja, $672 \mathrm{~m}^{3 /}$ mês, constituindo o volume de água a ser economizado mensalmente.

Em dinheiro, esse projeto não reproduz economia para a indústria estudada, pois todo o processo produtivo é abastecido com água do poço, pela qual a empresa não paga, já que, em Sergipe, ainda não foi implementado o instrumento de cobrança pelo uso da água.

Porém, supondo-se que a fonte dessa água fosse a Compainha de Saneamento de Sergipe, que cobra, atualmente, para a categoria industrial, uma tarifa de $\mathrm{R} \$ 18,21$ (para consumo superior a $\left.30 \mathrm{~m}^{3}\right)$ (DESO, 2018), a im- 
plantação do sistema de reúso de água implicaria em uma economia de $\mathrm{R} \$ 12.237,12 / \mathrm{mês}$. Portanto, em aproximadamente 1 ano e 10 meses, a indústria passaria a receber o retorno do seu investimento.

\subsubsection{Viabilidade Social (Aceitabilidade da água para reúso)}

O questionário de aceitabilidade foi respondido por uma amostra de 100 funcionários da indústria. As repostas encontram-se disponíveis no Quadro 1.

Quadro 1 - Respostas do questionário de aceitabilidade.

\begin{tabular}{|l|c|c|c|}
\hline Perguntas / Respostas & SIM & NÃO & 14 \\
\hline Você sabia que uma água que já foi utilizada em uma atividade pode ser utilizada em outra atividade? & 86 & 92 \\
\hline Você adotaria o reúso de água em sua casa para diminuir o consumo de água? & 8 & 92 \\
\hline Você adotaria o reúso de água independentemente do valor que custasse? & 79 & 21 & 79 \\
\hline
\end{tabular}

Fonte: Elaborada pelas autoras.

De acordo com o Quadro 1, em relação à aceitabilidade ambiental, foi encontrado o valor de $p=92 \%$ e, quanto à aceitabilidade econômica, encontrou-se $p=79 \%$.

Pelas respostas, observou-se que os entrevistados apresentam conhecimento em relação à técnica de reúso de água; entretanto, aparentemente desconhecem as dificuldades de adquirir um nível de potabilidade para o consumo desta, uma vez que houve um percentual de $92 \%$ de aceitabilidade em adotá-la para diminuir o consumo de água com seu uso.

\subsubsection{Cálculo do erro máximo de estimação e construção dos intervalos de confiança}

A determinação do erro máximo de estimação e dos limites dos intervalos de confiança (LI e LS) foi realizada com o auxílio do software Excel, usando as Eq. 1 e 2. Nos cálculos, utilizou-se N = 272 (quantidade total de funcionários da indústria) e adotouse o nível de confiança de $95 \%$ ( $\alpha=0,05$ e Z=1,96).

$\mathrm{Na}$ Tabela 2, foram apresentados os resultados para cada variável analisada. Para as duas variáveis, foi utilizada a distribuição normal e o erro máximo de estimação foi corrigido.

Tabela - Resultados das variáveis analisadas nos questionários de aceitabilidade.

\begin{tabular}{|c|c|c|c|c|c|c|c|}
\hline & Variáveis & $\mathbf{n}$ & $\mathbf{p}$ & $\mathbf{e 0}$ & e0 corrigido & LI & LS \\
\cline { 2 - 7 } Reúso de água & $\begin{array}{c}\text { Aceitabilidade } \\
\text { ambiental }\end{array}$ & $\mathbf{1 0 0}$ & $\mathbf{0 , 9 2}$ & $\mathbf{0 , 0 5}$ & $\mathbf{0 , 0 4}$ & $\mathbf{0 , 8 8}$ & $\mathbf{0 , 9 6}$ \\
\cline { 2 - 8 } & $\begin{array}{c}\text { Aceitabilidade } \\
\text { econômica }\end{array}$ & 100 & 0,79 & 0,08 & 0,06 & 0,73 & 0,85 \\
\hline
\end{tabular}

Fonte: Elaborada pela autora.

Por fim, com os dados apresentados na Tabela 2, foi possível construir os intervalos de confiança para cada variável, utilizando a Eq. 3.

- Aceitabilidade ambiental

$$
P(0,88 \leq \mu \leq 0,96) \simeq 95 \%
$$

- Aceitabilidade econômica

$$
\mathrm{P}(0,73 \leq \mu \leq 0,85) \simeq 95 \%
$$

Com isso, conclui-se que, em se tratando da aceitabilidade ambiental, há $95 \%$ de probabilidade de que a verdadeira proporção populacional de aceitabilidade esteja entre $88 \%$ e $96 \%$, bem como para a aceitabilidade econômica há 95\% de probabilidade de que a verdadeira proporção populacional de aceitabilidade esteja entre $73 \%$ e $85 \%$. 
Portanto, pode-se afirmar que o reúso de água apresenta um bom nível de aceitabilidade social em ambos os critérios analisados.

\section{CONCLUSÃO}

Diante dos resultados obtidos, verificou-se que, quanto ao aspecto econômico, a implementação dessa técnica requer um alto investimento inicial e, para a empresa analisada, não traz retorno financeiro, já que esta não paga pela água captada por meio dos poços, que é utilizada em todo o processo produtivo. Porém, na ocasião da efetivação da cobrança, considerando o alto consumo de água na etapa de granulação e em toda a indústria, poderia trazer retorno em pouco tempo. Considerando, por exemplo, que essa água fosse proveniente da Compainha de Saneamento de Sergipe, a implantação do sistema de reúso de água implicaria em uma economia de $\mathrm{R} \$ 12.237,12$ mensais e o prazo para o retorno do investimento seria de, aproximadamente, 1 ano e 10 meses.

Quanto ao aspecto ambiental, encontrou-se um resultado favorável, já que são economizados $672 \mathrm{~m} 3 / \mathrm{mês}$, ou seja, todo esse volume de água deixa de ser retirado dos corpos hídricos mensalmente. Cabe ressaltar, portanto, a preocupação ambiental da empresa, já que esta, por enquanto, não tem retorno financeiro com a adoção do sistema de reúso.

No aspecto social, destacou-se a alta aceitabilidade do sistema de reúso, tanto no critério econômico como no ambiental, com $95 \%$ de probabilidade de que a proporção populacional de aceitabilidade esteja entre $88 \%$ e $96 \%$ para o critério ambiental e entre $73 \%$ e $85 \%$ para o critério econômico. Esses valores indicam que a maioria das pessoas adotaria essa técnica, independentemente do custo inicial, para reduzir o consumo de água.
Conclui-se, portanto, que é viável implementar um sistema de reúso em indústria de revestimento cerâmico, e vale destacar a necessidade de implantação de instrumentos de gestão na bacia hidrográfica em que a indústria está inserida, principalmente a cobrança pelo uso da água (exemplos de bacias como São Francisco, PCJ - Piracicaba, Capivari e Jundiaí, entre outras), a qual traria benefícios financeiros e operacionais, por meio do desenvolvimento de melhorias na própria bacia e incentivaria ainda mais o uso racional de água por parte dos grandes usuários, como é o caso da indústria de cerâmica.

\section{CONTRIBUIÇÃO DOS AUTORES}

Todos os autores contribuíram de forma igualitária.

\section{REFERÊNCIAS}

ABCERAM - Associação Brasileira de Cerâmica. Informações Técnicas: processos de fabricação. Disponível online em: < http://abceram.org.br/processo-de-fabricacao/>. Acesso em 04.04.2017.

ALBUQUERQQUE, T. M. A. Seleção Multicriterial de Alternativas para o Gerenciamento da Demanda de Água na Escala de Bairro. 2004. 215 f. Dissertação (Mestrado em Engenharia Civil e Ambiental - Geotecnia) - Universidade Federal de Campina Grande, Paraíba. 2004.

ANA - Agência Nacional de Águas. Conjuntura dos Recursos Hídricos do Brasil 2014: Encarte especial sobre a crise hídrica. Disponível online em: http://www2.ana.gov.br/Paginas/default. aspx. 2015a. Acesso em: 08/06/2016

ANA - Agência Nacional de Águas. Conjuntura dos Recursos Hídricos do Brasil 2015. Disponível online em: http://www2.ana. gov.br/Paginas/default.aspx. 2015b. Acesso em: 08/06/2016.

ANA - Agência Nacional de Águas. Conjuntura dos Recursos Hídricos do Brasil 2016. Disponível online em: http://www2.ana. gov.br/Paginas/default.aspx. 2016. Acesso em: 12/02/2017.

ANA - Agência Nacional de Águas. Instrumentos de Gestão. Disponível online em: http://www2.ana.gov.br/Paginas/default.aspx. 2017a. Acesso em: 14/03/2017.

ANA - Agência Nacional de Águas. Dispõe sobre a redução temporária da descarga mínima dos reservatórios de Sobradinho e Xingó, no rio São Francisco, para até 31 de março de 2019, e dá 
outras providências. Resolução n. 90, de 26 de novembro de 2018. Brasília - DF. 2018.

ANFACER - Associação Nacional dos Fabricantes de Cerâmica. Relatório de atividades 2011/2014. Disponível online em: < http://www.anfacer.org.br/principais-resultados>. Acesso em: 18/03/2017.

APHA - American Public Health Association. Standard Methods for the Examination of Water and Wastewater. $22^{\text {th }}$ edition. Washington: APHA, 2012. ISBN-13 : 978-0875530130.

BOLFARINE, H.; BUSSAB, W. O. Elementos de amostragem. Universidade de São Paulo. 2004. 269p.

CEHOP - Companhia Estadual de Habitação e Obras Públicas. Orçamento de Obras de Sergipe. Disponível online em: < http:// www.cehop.se.gov.br/orse/>. Acesso em: 14/06/2017.

CETESB - Companhia Ambiental do Estado de São Paulo. Uso Racional de água. Disponível online em: < http://consumosustentavel.cetesb.sp.gov.br/casos-de-sucesso/uso racional de-agua/>. Acesso em: 05/07/2016.

CIRILO, J. A. Crise hídrica: desafios e superação. Revista USP. São Paulo. 2015. Jul/Ago/Set; n. 106, p. 45-58. https://doi. org/10.11606/issn.2316-9036.v0i106p45-58
DESO = Companhia de abastecimento de Sergipe - Quadro tarifário. Disponível online em: https://www.deso-se.com.br/v2/index. php/clientes/quadro-tarifario. 2018. Acesso em: 12/01/2019.

LOPES, C. L. J. Gerenciamento dos Recursos Hídricos e o Processo de Internalização da variável água nas indústrias. 2006. 151 p. Dissertação (Mestrado em Geociências) - Universidade Estadual de Campinas, São Paulo. 2006.

MIERZWA, J. C. O uso racional e o reúso como ferramentas para o gerenciamento de águas e efluentes na indústria: estudo de caso da Kodac brasileira. 2002. 367 f. Tese (Doutorado em Engenharia Hidráulica e Sanitária) - Escola Politécnica da Universidade de São Paulo, São Paulo. 2002.

REIS, M. M. Inferência Estatística: Estimação de parâmetros. Dez, 2012. 19 F. Notas de Aula.

RIBEIRO, F. M. G. Uso da água na indústria sucroalcooleira: estudo de caso. 2011. 183 p. Dissertação (Mestrado em Engenharia Civil) - Universidade Estadual de Campinas, São Paulo. 2011.

SETTI, A. A.; LIMA, J. E. F. W.; CHAVES, A. G. M.; PEREIRA, I. C. Introdução ao gerenciamento de Recursos Hídricos. Brasília: Agência Nacional de Energia Elétrica, Superintendência de Estudos e Informações Hidrológicas, 2000. 207 p. 